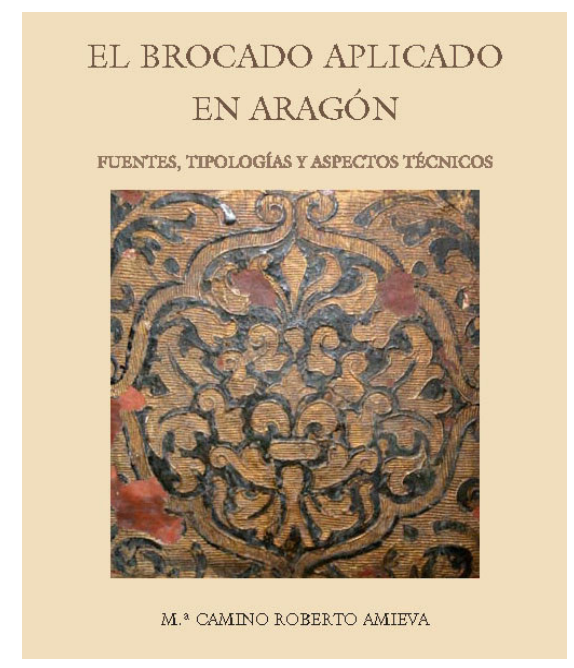

\section{El brocado aplicado en Aragón. Fuentes, tipologías y aspectos técnicos}

\section{Ma Camino Roberto Amieva}

Editado por: El Instituto de Estudios Altoaragoneses, Diputación de Huesca. 33 pág. más un CD. Ilustraciones en color. 22,5 × 22,5 cm. Huesca, 2014

ISBN 978-84-8127-267-3.
El libro recoge la revisión de la tesis de doctorado defendida por la autora en 2013 en la Universidad de Sevilla sobre la técnica de policromía conocida como "brocado aplicado" en el ámbito geográfico de Aragón.

Esta técnica de decoración en relieve, utilizada en Europa durante los últimos años del siglo XV y a lo largo del XVI, se extiende de manera particular en esta región, con una cronología amplia, abundancia de ejemplos conservados y una nutrida documentación que permiten a C. Roberto extraer conclusiones fundamentadas y abrir hipótesis de trabajo de gran interés.

Diversas razones de logística han limitado el trabajo a las provincias de Huesca y Zaragoza, obviando las diócesis de Teruel y Albarracín, por lo que en un futuro podrá ser completado para tener una visión exhaustiva del territorio definido en el título. Las piezas estudiadas pertenecen en su mayoría a retablos en madera policromada, añadiéndose algunas tallas exentas y un armario.

La publicación se estructura en cinco capítulos. Los dos primeros describen la técnica y la enmarcan en los ámbitos geográfico, material y de investigación. Los siguientes se centran ya en el objeto de estudio, abordando la técnica del brocado en Aragón, y examinándola desde el punto de vista histórico, formal y tecnológico.

1. El origen del brocado aplicado: contexto histórico-artístico, materiales y técnicas.

Introducción al entorno social y artístico de los siglos en que se desarrolló esta técnica, y a los materiales y prácticas empleados habitualmente en la decoración polícroma en escultura, con especial atención a las de relieve y aplicación.

2. Evolución histórica, elaboración y fuentes documentales del brocado aplicado.

Contextualización del brocado aplicado a través de la relación de los textiles imitados, el origen geográfico de la técnica y su difusión en Europa (principalmente en España); la clasificación de los motivos reproducidos y modelos; el proceso técnico de elaboración; las fuentes documentales históricas y el estado de la cuestión de las investigaciones en Europa y España, con una revisión crítica sobre los diversos trabajos consultados.

\section{Estudio y análisis del brocado aplicado en Aragón.}

La autora, a partir de las 52 piezas estudiadas, establece el ámbito histórico y cronológico del empleo de la técnica en la región, desvelando testimonios muy tardíos que amplían el marco hasta 1597. Al mismo tiempo determina el género de obras que decora y la evolución en su localización, así como la tipología del brocado (yuxtapuesto, aislado o en bandas), los motivos empleados (geométricos, vegetales, etc.), sus dimensiones y formatos, la tecnología de sus diseños (texturas, relieves, etc.) y sus características singulares. Lo que le permite revelar modelos iguales o similares utilizados en distintas piezas.

4. Los autores del brocado: los pintores.

C. Roberto reflexiona sobre lo expuesto hasta la fecha por distintos investigadores sobre la autoría de ejecución 
del brocado, centrándose posteriormente en el funcionamiento de los gremios de artistas en Aragón y analizando los autores documentados en relación a esta técnica. A partir de estos datos y apoyándose en la repetición de motivos de brocado, emite hipótesis sobre la autoría de la policromía de ciertos retablos.

5. Los materiales constitutivos de los brocados aragoneses y su deterioro.

La autora va exponiendo la naturaleza y composición de los estratos existentes en los brocados aplicados de las tres tipologías: aislados, lineales y yuxtapuestos. El apartado comienza por el soporte, generalmente aunque no siempre de madera, la base, el adhesivo, el relleno, la lámina de estaño, el dorado y el policromado. Establece cuales son las variantes observadas o establecidas en los análisis realizados de varias obras, recurriendo a una amplia bibliografía y aportando tablas clarificadoras. También establece hipótesis en relación con su funcionalidad o el periodo de ejecución.

En la parte que se refiere al deterioro de los brocados hace hincapié en la retracción de la cola empleada como adhesivo y la inestabilidad del estaño en una atmósfera oxidante y en contacto con un metal noble como el oro. También explica que la alteración de los brocados ha hecho que su morfología haya sufrido grandes transformaciones y pérdidas en las obras realizadas con esta interesante técnica de la policromía tardomedieval.

Anexo. Resultados de los análisis consultados.

En libro se completa con un apartado de bibliografía y un CD-ROM que contiene el catálogo de las obras estudiadas, con datos de identificación y documentación diversa sobre los motivos, incluyendo dibujos parciales o totales de los mismos.

Esta publicación presenta el interés de constituirse en un catálogo riguroso y completo de una determinada zona de estudio, aunando datos extraídos de la labor de campo, propia de la formación de conservadores y restauradores, con la documentación y el contexto histórico-artístico, más habitual en historiadores. Por tanto su lectura es adecuada para conservadores, restauradores y científicos dedicados al Patrimonio Cultural.

Camino Roberto es doctora en Bellas Artes por la Universidad de Sevilla. Trabajó como restauradora y coordinadora en intervenciones en retablos policromados y pintura de caballete y mural. Desde 2007 imparte clases en la Escuela Superior de Conservación y Restauración de Bienes Culturales de Aragón, en las especialidades de Restauración de Obras Pictóricas y Escultóricas. La publicación de su tesis ha supuesto un avance importante en la investigación de esta técnica de policromía en el es- tado español y el primer ejemplo en nuestro país de un estudio relacionado en una zona geográfica amplia y con numerosos ejemplos.

\section{Maite Barrio Olano}

Albayalde-conservatio 